\title{
Radiculopathy in the setting of lumbar nerve root compression due to an extradural intraforaminal lipoma: a report of 3 cases
}

\author{
Daniel B. Loriaux, BS, Owoicho Adogwa, MD, MPH, and Oren N. Gottfried, MD \\ Division of Neurosurgery, Duke University Medical Center, Durham, North Carolina
}

\begin{abstract}
A true adult spinal lipoma is an exceedingly rare cause of lumbar compression neuropathy. Only 5 cases of true extradural intraforaminal lipomas have been documented in the medical literature. The diagnostic criteria and treatment guidelines for this specific lipoma have yet to be established. This report features 3 histologically confirmed cases of extradural intraforaminal spinal lipomas that recently presented to the authors' practice. In addition, the literature was surveyed to include the 5 previously reported cases of true adult extradural intraforaminal spinal lipomas. The consistency in presentation, response to surgical intervention, and postoperative recovery in these 8 cases supports surgical intervention at the time of diagnosis. The authors' findings support elevated clinical suspicion, efficient diagnosis based on MRI, and early surgical intervention for this rare pathological entity. All cases presented in this report were symptomatic and occurred in the absence of other significant pathologies such as general spinal epidural lipomatosis, intradural lesions, tethering, or severe degenerative stenosis or herniated discs. The clinical, neuroradiological, and histological findings characteristic of a true adult extradural intraforaminal lipoma are emphasized to differentiate this lesion from the more common etiologies for lumbar compression neuropathy. Heightened awareness and clinical suspicion for the focal, foraminal spinal lipoma as a cause of radiculopathy symptoms will enable more efficient diagnosis and treatment.
\end{abstract}

http://thejns.org/doi/abs/10.3171/2014.11.SPINE14693

KEY WORDS spine; adult extradural intraforaminal spinal lipoma; radiculopathy; lumbar

$\Lambda$ $\mathrm{N}$ extradural intraforaminal spinal lipoma in the absence of myelospinal dysraphism is an exceedingly rare pathological entity.,15 Clinically, this lesion manifests as a unilateral radiculopathy refractory to conservative management. Although true adult spinal lipomas account for only $0.4 \%-0.8 \%$ of all intraspinal tumors, ${ }^{15}$ the associated constellation of lumbosacral radiculopathy symptoms are estimated to affect 3\%-5\% of the adult population in the US. ${ }^{7,12}$ The differential for common lumbar radiculopathy is vast and most frequently can be attributed to common pathologies such as disc herniation or spinal stenosis. Next to these highly prevalent etiologies, the possibility of compressing lipomatous tissue should not be excluded. Magnetic resonance imaging is the gold standard in diagnostic imaging for lumbar compression neuropathy due to a potential extradural intraforaminal lipoma. 5,11

Magnetic resonance imaging of a lipomatous lesion, such as a true adult intraforaminal lipoma, angiolipoma, or spinal epidural lipomatosis (SEL), will reveal hyperintensity on T1-weighted sequences with decreased to interme- diate intensity on T2-weighted sequences. ${ }^{5,8,10,13}$ Diagnosis is further complicated by the difficulty in differentiating a true lipoma from more prevalent lesions such as an angiolipoma or SEL. If surgical exploration is performed, careful histological examination of the excised mass is essential for accurate differentiation of a true lipoma from an angiolipoma.

The objective of our retrospective case series and survey of the literature is to increase clinical suspicion for this rare etiology of lumbar radiculopathy. We encourage the differentiation of true spinal lipomas from SEL, angiolipomas, and degenerative sources of lumbar radiculopathy via diagnostic MRI and histopathology. $1,5,9,10$

\section{Case Reports \\ Case 1 \\ History and Examination}

A 38-year-old nonobese man presented to our practice with a medical history significant for chronic left L-5 radiculopathy. The patient's chief complaint was progres-

ABBREVIATION SEL $=$ spinal epidural lipomatosis

SUBMITTED July 17, 2014. ACCEPTED November 4, 2014.

INCLUDE WHEN CITING Published online April 3, 2015; DOI: 10.3171/2014.11.SPINE14693.

DISCLOSURE The authors report no conflict of interest concerning the materials or methods used in this study or the findings specified in this paper. 
sively worsening weakness and "shooting" left-sided radicular pain. The radiculopathy had proven refractory to all attempted conservative treatment modalities over the preceding 6-year interval. Repeat MRI of the lumbar spine revealed a left L5-S1 lumbosacral mass that involved the entire left L-5 foramen with caudal displacement of the L-5 nerve root (Fig. 1).

\section{Operation}

Elective left laminectomy, medial facetectomy, foraminotomy, and resection of an encapsulated lesion were performed without complication. The lesion was excised, and interval decompression of the involved foramen and nerve root was achieved. Gross examination of the lesion revealed a lobulated, yellow fatty mass encapsulated by a thin layer of fibrous tissue. Histopathology showed no evidence of vascular atypia and was consistent with a true adult extradural intraforaminal lipoma.

\section{Postoperative Course}

Postoperatively, the patient recovered without complication. At his 3-month follow-up visit, he reported markedly attenuated radicular symptoms; there was a drastic reduction in his low-back pain, left leg pain, paresthesia, and weakness. Steady improvement was noted at the 6and 10-month follow-up visits with continued alleviation of his left lower-extremity radiculopathic pain. By the 10-month follow-up, he was comfortable and ambulating normally with full motor strength and range of motion.

\section{Case 2}

\section{History and Examination}

A 40-year-old man presented to our practice with refractory left L-3 radiculopathy manifesting as persistent weakness, paresthesia, and severe radiating pain. The radiculopathy was refractory to 2 years of conservative medical management. Initial MRI in the patient suggested a radiculopathy caused by lumbar stenosis due to foraminal lumbar epidural lipomatosis rather than an organized L3-4 lipoma causing cranial displacement of the root within the foramen (Fig. 2).
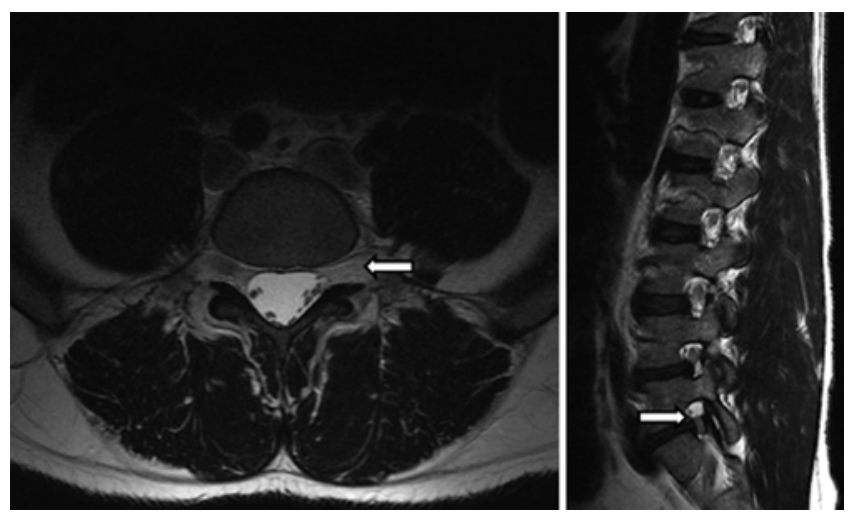

FIG. 1. Case 1. Left: Preoperative axial T2-weighted MR image demonstrating a left intraforaminal lipoma (arrow) with an empty foramen at this level because of caudal displacement of the root compared with the nerve root seen on the right. Right: Sagittal image showing caudal displacement of the root (arrow) by lipoma.
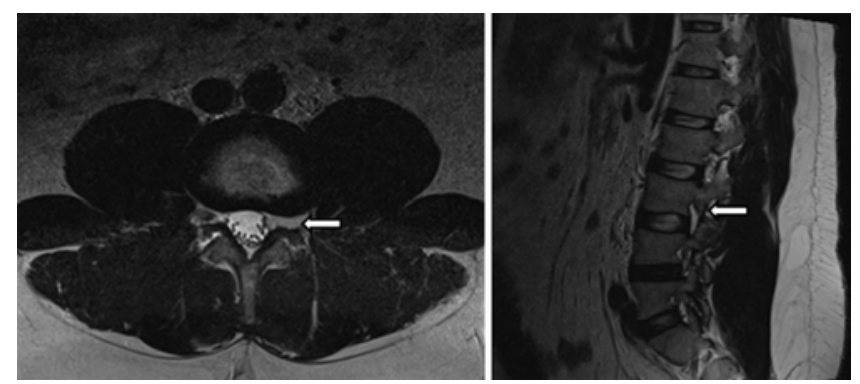

FIG. 2. Case 2. Left: Preoperative axial T2-weighted MR image demonstrating a left intraforaminal lipoma (arrow) with an empty foramen at this level because of cranial displacement of the root compared with the nerve root seen on the right. Right: Sagittal image showing cranial displacement of the root (arrow) by lipoma.

\section{Operation}

Elective surgical intervention with L3-4 left laminectomy, medial facetectomy, foraminotomy, and resection of the mass was performed. Gross examination in surgery revealed a yellow, lobulated epidural mass within a fibrous capsule. Histology confirmed adipose tissue in the absence of vascular atypia, most consistent with a true adult lipoma.

\section{Postoperative Course}

The elective procedure was tolerated well by the patient, and there were no postoperative complications. At the 3-month follow-up, the patient showed marked improvement in his symptoms with alleviated pain and significantly improved strength in the left lower extremity. At the 6-month follow-up, he was ambulating at the baseline level with resolution of the lumbar radiculopathy. He had maintained these results without complication or symptomatic recurrence at his 12-month follow-up visit.

\section{Case 3}

\section{History and Examination}

A 44-year-old man presented with the chief complaint of chronic radicular pain in an L-4 distribution pattern. Conservative treatment efforts consisted of transcutaneous electrical nerve stimulation, epidural steroid injections, physical therapy, acupuncture, and analgesic pharmacotherapy. Magnetic resonance imaging revealed an L-4 intraforaminal lesion with mass effect on the lateral thecal sac and nerve root at the foramen (Fig. 3). There was no evidence of severe degenerative stenosis.

\section{Operation}

Elective surgical intervention with L4-5 left laminectomy, facetectomy, and foraminotomy for resection of the mass was performed without complication. An encapsulated lipomatous lesion was excised, and the mass was confirmed to contain true lipomatous tissue without vascular atypia on final histopathology.

\section{Postoperative Course}

The patient's postoperative course was encouraging, without complication or relapse. At his 3-month follow-up assessment, he reported drastic improvement in his radiculopathic pain as well as significantly improved strength 

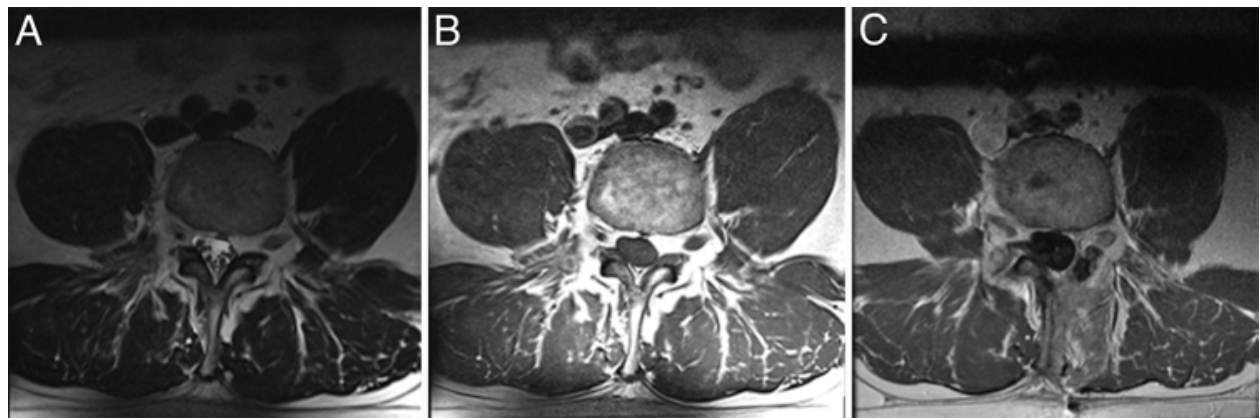

FIG. 3. Case 3. Preoperative T2-weighted (A) and T1-weighted (B) MR images demonstrate an intraforaminal lipoma at L4-5 with left lateral recess protrusion and proximity to the exiting extraforaminal L-4 nerve root. Postoperative MRI at 6 months performed after a fall (C) showed resection of the lipoma without impingement on the left lateral recess.

in his left lower extremity. At the 6-month follow-up, he demonstrated continued improvement in strength and ambulation. He did have a minor trauma, with increased back pain prompting lumbar MRI during an emergency room visit. The imaging did show interval resection of the foraminal lipoma without impingement on the lateral recess. This progress was maintained at the 12-month follow-up. The patient's only complaint at this visit was mild back pain, which was attributed to a traumatic incident.

\section{Discussion}

Spinal lipomas are unique pathological entities rarely observed in the absence of myelospinal dysraphism. ${ }^{4}$ Given the rarity and characteristically benign MRI findings of a true spinal lipoma, this lesion can be easily overlooked or misdiagnosed. Symptoms related to mass effect and secondary compressive myelopathy from a lipomatous mass could be caused by a true lipoma, an angiolipoma, or an SEL. True adult lipomas must be distinguished from both an angiolipoma and an SEL. ${ }^{15}$ The process of differentiating between these lipomatous lesions begins with a survey of patient risk factors for SEL. Six of the 8 patients considered in this report presented with none of the 3 primary characteristics associated with SEL: chronic exogenous steroid use, endocrinopathy, and obesity (Table 1). ${ }^{3,11}$ The remaining 2 patients presented with only 1 of the established SEL risk factors: obesity. Magnetic resonance imaging can be used to reliably differentiate a true adult lipoma from an SEL, which consists of a diffuse overgrowth of epidural adipose tissue within the spinal canal. To differentiate a true adult lipoma from an angiolipoma, however,

TABLE 1. Summary of radiculopathy cases attributable to extradural intraforaminal lipoma*

\begin{tabular}{|c|c|c|c|c|c|}
\hline Authors \& Year & $\begin{array}{l}\text { Age (yrs), } \\
\quad \text { Sex }\end{array}$ & $\begin{array}{c}\mathrm{BMI} \\
\left(\mathrm{kg} / \mathrm{m}^{2}\right)\end{array}$ & Presentation & Imaging Findings & Postop Complications \\
\hline Present Case 1 & $38, M$ & 24.8 & L-5 radiculopathy & $\begin{array}{l}\text { L5-S1 It mass involving entire fora- } \\
\text { men; } 1.1 \times 1.1 \times 0.3-\mathrm{cm} \text { epidural } \\
\text { mass; no degenerative stenosis }\end{array}$ & $\begin{array}{l}\text { None; significant improvement of symptoms by } \\
6 \text {-mo FU; continued improvement in back \& } \\
\text { leg pain by } 10 \text {-mo FU }\end{array}$ \\
\hline Present Case 2 & $40, \mathrm{M}$ & 40.0 & L-3 radiculopathy & $\begin{array}{l}\text { L3-4 It lat recess \& foraminal mass; } \\
2.5 \times 1.6 \times 0.3-\mathrm{cm} \text { epidural mass; } \\
\text { no degenerative stenosis }\end{array}$ & $\begin{array}{l}\text { None; significant improvement of symptoms by } \\
\text { 6-mo FU; complete resolution of leg pain by } \\
\text { 12-mo FU }\end{array}$ \\
\hline Present Case 3 & $44, \mathrm{M}$ & 29.0 & L-4 radiculopathy & $\begin{array}{l}\text { Lt L4-5 foraminal mass; } 1.1 \times 0.8 \times \\
0.2-c m \text { epidural mass; no degen- } \\
\text { erative stenosis }\end{array}$ & $\begin{array}{l}\text { None; significant improvement of symptoms by } \\
6 \text {-mo FU; continued resolution of symptoms } \\
\text { w/ only mild back pain noted at } 12-\text { mo FU }\end{array}$ \\
\hline $\begin{array}{l}\text { Zevgaridis et al., } \\
2008\end{array}$ & $62, F$ & $<30$ & L-5 radiculopathy & $\begin{array}{l}\text { Compression of It L-5 nerve root by } \\
\text { an extradural intraforaminal mass; } \\
\text { no degenerative stenosis }\end{array}$ & None \\
\hline Kim et al., 2012 & $55, \mathrm{M}$ & 31.6 & L-5 radiculopathy & $\begin{array}{l}\text { Epidural mass posterior to L- } 5 \text { verte- } \\
\text { bral body }\end{array}$ & $\begin{array}{l}\text { None; complete resolution of symptoms by } \\
2-y r \text { FU }\end{array}$ \\
\hline \multirow[t]{3}{*}{$\begin{array}{l}\text { Dierckx et al., } \\
1987\end{array}$} & $43, M$ & $<30$ & S-1 radiculopathy & $\begin{array}{l}\text { Extradural filling defect at It L-5 } \\
\text { vertebra on myelogram }\end{array}$ & None; complete resolution by 3-mo FU \\
\hline & $62, \mathrm{M}$ & $<30$ & L-5 radiculopathy & $\begin{array}{l}\text { Extradural filling defect on my- } \\
\text { elogram w/ minor L5-S1 disc } \\
\text { prolapse }\end{array}$ & None; complete resolution by $10-\mathrm{mo}$ FU \\
\hline & $56, \mathrm{M}$ & $<30$ & L-4 radiculopathy & $\begin{array}{l}\text { Extradural filling defect in L3-4 on } \\
\text { myelogram w/ some degeneration }\end{array}$ & $\begin{array}{l}\text { None; symptomatic improvement noted post- } \\
\text { operatively }\end{array}$ \\
\hline
\end{tabular}

$\mathrm{BMI}=$ body mass index; $\mathrm{FU}=$ follow-up.

* There was no preoperative endocrinopathy in any of the listed cases, and steroid therapy was not used in any of the listed cases. 
histopathological study is required. The high prevalence of radiculopathy due to common degenerative pathologies, such as disc herniation or degenerative foraminal stenosis, can also limit consideration of the rare extradural intraforaminal lipoma., ${ }^{72,14}$ As a result of its challenging diagnosis and low clinical suspicion, a true adult spinal lipoma is very likely underrepresented in the medical literature..$^{8,15}$

The 3 patients who presented to our practice had endured years of equivocal MRI studies, failed conservative therapies, and inconclusive assessments by multiple spine specialists and surgeons. For all 3 patients, we confirmed our diagnosis of extradural intraforaminal lipoma via macroscopic and histological inspection after total resection. Contrasting the findings in our 3 patients with those in the 5 cases from the literature (Table 1), we were able to demonstrate high consistency in clinical presentation, diagnostic MRI, and responsiveness to surgical intervention. On postoperative follow-up, all patients with a confirmed extradural intraforaminal lipoma demonstrated significant alleviation of radicular pain and reversal of preoperative neurological deficits by the 3- to 6-month interval. ${ }^{2,6,15}$

Overall, we found the MRI findings to be predictable across all cases. All 3 of our patients had a high-signalintensity epidural lesion on T1- and T2-weighted imaging that was located within a foramen ipsilateral to the side of symptoms, causing possible impingement of the lateral thecal sac (Figs. 1-3). Magnetic resonance imaging consistently showed displacement of the nerve root cranially or caudally, leading to the "empty foramen sign." This "missing root" on axial images is identifiable on sagittal imaging in which it is possible to see the root displaced up or down. Although diagnosis of a true adult spinal lipoma is challenging given the low clinical suspicion and subtle neuroradiological findings, the highly favorable prognosis and early recovery achievable through surgical intervention merits screening for this lesion in patients who suffer from refractory radiculopathic pain in the absence of degenerative stenosis or herniated disc.

\section{Conclusions}

In summary, although MRI offers a means for early identification and treatment of an extradural intraforaminal lipoma, the neuroradiological diagnosis for a true spinal lipoma is a challenging task. The subtle MRI findings for an extradural intraforaminal lipoma can be easily overlooked or dismissed within the realm of normal anatomical variation; therefore, clinical suspicion for these lesions must increase in the presence of a high T1 and T2 signal occupying the lateral recess and foramen with unilateral displacement of a nerve root cranially or caudally in the absence of severe degenerative findings. The empty foramen sign, in which the nerve root on the side of radiculopathy is not easily identifiable, is helpful in diagnosing the extradural intraforaminal lipoma (Figs. 1-3). Ultimately, histopathology is essential for accurate diagnosis. The 8 cases considered in this report support early surgical intervention for a symptomatic extradural lipoma. The prognosis following resection of this lesion has been favorable. Because of its rarity, the extradural intraforaminal lipoma continues to lack definitive treatment guidelines. Our findings in this small case series and retrospective analysis strongly support surgical intervention for symptomatic lesions. Although we report symptomatic improvement at 10-12 months after surgery, longer-term follow-up is needed to determine if patients are at risk for delayed recurrence.

\section{References}

1. Beges C, Rousselin B, Chevrot A, Godefroy D, Vallee C, Berenbaum F, et al: Epidural lipomatosis. Interest of magnetic resonance imaging in a weight-reduction treated case. Spine (Phila Pa 1976) 19:251-254, 1994

2. Dierckx RA, Pallua A, Mayr U, Aichner F, Gerstenbrand F: Spinal extradural lipomas: a report on three patients, in Poeck HVK, Hacke W, Schneider R (eds): Verhandlungen der Deutschen Gesellschaft für Neurologie: Neuroimmunologie, Spinale Krankheiten, Neuropsychologie, Metabolische Enzephalopathien, Neurologische Notfälle, Interventionelle Neuroradiologie. Berlin: Springer-Verlag, 1987, Vol 4, p 653

3. Haid RW Jr, Kaufman HH, Schochet SS Jr, Marano GD: Epidural lipomatosis simulating an epidural abscess: case report and literature review. Neurosurgery 21:744-747, 1987

4. Hungs M, Paré LS: Spinal angiolipoma: case report and literature review. J Spinal Cord Med 31:315-318, 2008

5. Ishikawa Y, Shimada Y, Miyakoshi N, Suzuki T, Hongo M, Kasukawa Y, et al: Decompression of idiopathic lumbar epidural lipomatosis: diagnostic magnetic resonance imaging evaluation and review of the literature. J Neurosurg Spine 4:24-30, 2006

6. Kim HK, Koh SH, Chung KJ: Solitary epidural lipoma with ipsilateral facet arthritis causing lumbar radiculopathy. Asian Spine J 6:203-206, 2012

7. Kinkade S: Evaluation and treatment of acute low back pain. Am Fam Physician 75:1181-1188, 2007

8. Pagni CA, Canavero S: Spinal epidural angiolipoma: rare or unreported? Neurosurgery 31:758-764, 1992

9. Robertson SC, Traynelis VC, Follett KA, Menezes AH: Idiopathic spinal epidural lipomatosis. Neurosurgery 41:68-75, 1997

10. Rocchi G, Caroli E, Frati A, Cimatti M, Savlati M: Lumbar spinal angiolipomas: report of two cases and review of the literature. Spinal Cord 42:313-316, 2004

11. Rodrigues JC, Mortimer AM, Love S, Renowden SA: A rare cause of neural foraminal widening. J Radiol Case Rep 6:1-8, 2012

12. Tarulli AW, Raynor EM: Lumbosacral radiculopathy. Neurol Clin 25:387-405, 2007

13. Turgut M: Spinal angiolipomas: report of a case and review of the cases published since the discovery of the tumour in 1890. Br J Neurosurg 13:30-40, 1999

14. Valat JP, Genevay S, Marty M, Rozenberg S, Koes B: Sciatica. Best Prac Res Clin Rheumatol 24:241-252, 2010

15. Zevgaridis D, Nanassis K, Zaramboukas T: Lumbar nerve root compression due to extradural, intraforaminal lipoma. An underdiagnosed entity? J Neurosurg Spine 9:408-410, 2008

\section{Author Contributions}

Acquisition of data: Gottfried, Loriaux. Drafting the article: Loriaux. Critically revising the article: all authors. Reviewed submitted version of manuscript: Loriaux. Approved the final version of the manuscript on behalf of all authors: Gottfried. Study supervision: Gottfried.

\section{Correspondence}

Oren N. Gottfried, Division of Neurosurgery, Duke University, DUMC Box 3807, Durham, NC 27710. email: oren.gottfried@ dm.duke.edu. 